\title{
Short report. The AIDIT and IMPACT conference 2006: Outcomes and future directions
}

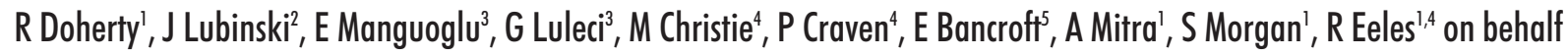 \\ of the IMPACT steering committee ${ }^{\dagger}$ and collaborators* \\ ITranslational Cancer Genetics Team, The Institute of Cancer Research, London, United Kingdom; 2International Hereditary Cancer Centre, Pomeranian Medical \\ University, Szczecin, Poland; ${ }^{3}$ Department of Medical Biology and Genetics, Faculty of Medicine, Akdeniz University, Antalya, Turkey; ${ }^{4}$ Research Services, The Institute \\ of Cancer Research, London, United Kingdom; ${ }^{5}$ The Royal Marsden NHS Foundation Trust, London, United Kingdom
}

Corresponding author: Rosalind Eeles MA, PhD, FRCR, FRCP, Reader in Clinical Cancer Genetics and Honorary Consultant in Cancer Genetics and Clinical Oncology, Cancer Genetics Unit, The Royal Marsden NHS Foundation Trust, Downs Road, Sutton, Surrey, SM2 5PT, United Kingdom, phone +44 20866138 97, fax +44 2087701489

Submitted: 12 January 2007

Accepted: 1 February 2007

\section{Introduction}

IMPACT (Identification of Men with a genetic predisposition to ProstAte Cancer: Targeted screening in $B R C A 7 / 2$ mutation carriers and controls) is an international collaboration investigating the utility of targeted prostate-specific antigen (PSA) screening for men at increased risk of prostate cancer due to inherited predisposition. Although the majority of prostate cancer occurs sporadically, it is recognized that family history plays a role in a significant number of cases: a family history either of prostate cancer alone [1], or of other cancers including breast and ovarian cancer [2]. Evidence of the link between single genes and prostate cancer risk is strongest for the BRCA1 and BRCA2 genes [3-5], with $B R C A 2$ in particular thought to lead to a relative risk of 4.65 (95\% Cl 3.48-6.22). This relative risk may be as high as 7.33 in men under the age of 65 years.

Population prostate cancer screening remains controversial because of the potential for detection of clinically insignificant disease in young men and the risk of over-treatment. There is increasing interest and concern in European countries about whether prostate cancer screening should be offered to the general population and whether this would lead to a reduction in mortality from prostate cancer. IMPACT raises the hypothesis that targeting screening at the men in the population who are known to have an increased risk of the disease might improve the effectiveness of prostate cancer screening. Beginning with a pilot of 100 patients, the IMPACT study ultimately aims to recruit a total of 850 carriers of mutations in BRCA1 and BRCA2 and 850 controls (men shown not to carry familial BRCA1/2 mutations by predictive genetic testing). Recruitment will be open for five years, followed by five years of follow-up.

In 2005, a project known as AIDIT (Advancing International co-operation and Developing Infrastructure for Targeted screening of prostate cancer in men with genetic predisposition) was awarded funding through the EC Framework 6 Programme as part of an endeavour to reduce research fragmentation and duplication, and to facilitate research collaboration across Europe. IMPACT currently includes collaborators from 24 countries. AIDIT's aim is to expand the IMPACT consortium within the associated candidate countries (ACCs) and new member states of the EU. The expansion of IMPACT is likely to benefit both the study and the research teams: a higher number of collaborating centres will allow access to a larger number of men at risk, making it possible to recruit as many carriers as are needed for the study, particularly in populations likely to harbour founder mutations; and for all collaborators - both new and existing - it is hoped that participation in AIDIT and IMPACT will foster an environment of ongoing interaction and learning. 


\section{The AIDIT and IMPACT conference}

To facilitate the international collaboration necessary for a project such as IMPACT, the AIDIT project provided funding for a conference, held from November $28^{\text {th }}$ to $30^{\text {th }} 2006$ in Szczecin, Poland. Attended by 117 delegates from 30 countries, it provided a unique opportunity to bring together researchers, clinicians and other experts from across the world. In accordance with AIDIT's aim to welcome potential collaborators from the ACCs, 20 delegates from a range of specialties in Romania, Bulgaria and Turkey attended, as well as a representative of the National Cancer Research Programme in Croatia, a country recently included as an ACC. A total of 32 delegates from nine of the ten new member states were also present.

The meeting was officially opened by Professor Przemyslaw Nowacki, Rector of Pomeranian Medical University, with welcome addresses provided by Prof Lubinski, conference host, and Dr Ros Eeles, Principal Investigator of IMPACT.

\section{Programme}

The conference programme included presentations from world leaders in fields as diverse as cancer genetics, urology, pathology, oncology and epidemiology. Abstracts and speaker biographies can be found on the IMPACT study website (www.impact-study.co.uk).

Day 1 focused on the scientific rationale for IMPACT, beginning with a summary from Dr Eeles of the study's background and aims. Subsequent presentations provided an overview of the genetics of inherited prostate cancer, including cancer risks in carriers of BRCA1 and BRCA2 mutations (Prof Doug Easton, UK), and a summary of other potential prostate cancer susceptibility genes being investigated in Poland (Prof Cezary Cybulski, Poland).

The use of PSA as a screening tool for prostate cancer stimulates debate across the world; several presentations therefore focused on screening both in the general population and in those with an inherited risk. Results from the ERSPC and ProtecT population-based prostate screening studies, respectively, were presented (Dr Monique Roobol, The Netherlands, and Prof Freddie Hamdy, UK), and an insight provided into the risks and benefits associated with both population and targeted screening (Dr Jane Warwick, UK). Prof Kari Hemminki (Germany) spoke about the effect of PSA screening and changing prostate cancer incidence on our understanding of familial prostate cancer risk.

The second day of the conference began with an update of progress in those countries beginning to recruit to IMPACT. In the UK, where 17 centres are participating, 51 of the 100 pilot patients had been recruited at the time of the conference: 15 carriers of BRCA1, 22 of $B R C A 2$, and 14 controls. Using a cut-off of $3 \mathrm{ng} / \mathrm{ml}$, four men have had raised PSA levels, with one carrier of a BRCA1 mutation having prostate cancer diagnosed on biopsy. Nonway has recruited 10 BRCA2 carriers, one of whom is awaiting biopsy after a raised PSA. Australia, Germany and Spain will begin recruitment in early 2007.

Participation in IMPACT requires that patients have undergone predictive genetic testing for the BRCAl or BRCA2 genes, but the infrastructure behind this testing, both technical and clinical, varies across the world and, at times, within countries. The rest of Day 2 therefore focused on issues related to setting up and maintaining this infrastructure. A clinical insight was provided by Prof Gareth Evans (UK), who discussed the management of individuals who carry mutations in BRCA1. Due to injury, Prof Kathryn Kash (USA) was unfortunately unable to present information on the ethical and psychological implications of genetic testing, but she was replaced by Prof Christopher Foster (UK), who spoke of the interface between prostate cancer genetics and pathology.

The current status of genetic testing across Europe was summarized by Prof Gert Matthiis, Deputy Coordinator of EuroGentest, a network for genetic test development, harmonization, validation and standardization. Perspectives were then provided from the UK, The Netherlands and Poland with regard to developing genetic testing services (Dr John Harvey, UK; Dr Jan Oosterwijk, The Netherlands; Prof Jan Lubinski, Poland). Prof Rodney Scott (Australia) broadened the discussion by raising future considerations for genetic testing, including improvements in technology and a better understanding of the role of modifier genes.

\section{International collaboration}

The final day of the conference was directed towards the advancement of international collaboration within IMPACT, with the main focus being the status of genetics and prostate cancer screening services in the ACCs. Discussion centred on funding, infrastructure, government support, public awareness and the role of clinicians and researchers in lobbying major stakeholders. Reports were provided by Dr Esra Manguoglu and Prof Guven Luleci (Turkey); Dr VladAlexandru Mixich and Prof Francisc Mixich (Romania); and Prof Stoyan Lalchev, Prof Ivanka Dimova and Dr Radka Kaneva (Bulgaria). Research teams in all of the ACCs were enthusiastic about participation in IMPACT.

The conference facilitated new working relationships, both within IMPACT and externally. Although the aim of 
the conference was to extend links with the ACCs and to develop the IMPACT consortium, it also played an important role in strengthening research ties in a range of fields. A meeting of this nature and size provided a unique opportunity to bring together individuals with similar research interests, but also allowed those with diverse backgrounds to share opinions and experience. New research projects were initiated, and existing projects broadened.

\section{Future considerations}

Following the conference, several new research teams will be integrated into the IMPACT consortium. Although not all will be able to begin active recruitment immediately, the fact that the study is being run over several years will allow time for development of procedures and services. A network of international experts can also share ideas about overcoming potential barriers to participation in the study. Since the conference, several teams have already begun to work on the issue of funding for genetic testing, either pursuing applications for research funding or approaching health ministries for support.

Those teams who do begin to recruit will be contributing to a growing resource which is likely to contribute a wealth of information to the field of prostate cancer genetics. It is hoped that IMPACT will not only determine whether PSA is an appropriate screening tool for men at high risk, but will identify potential new markers of prostate cancer risk and expand knowledge about the pathology of tumours in men carrying genes predisposing to prostate cancer. Close international collaboration will be fundamental to the achievement of these goals.

Further information about the IMPACT study can be found on the website www.impact-study.co.uk and expressions of interest are welcome.

\section{References}

1. Steinberg GD, Carter BS, Beaty TH, Childs B, Walsh PC. Family history and the risk of prostate cancer. Prostate 1990; 17: 337-347.

2. Tulinius $H$, Egilsson V, Olafsdottir GH, Sigvaldason H. Risk of prostate, ovarian, and endometrial cancer among relatives of women with breast cancer. BMJ 1992; 305: 855-857.

3. Thompson D, Easton DF, Breast Cancer Linkage Consortium. Cancer Incidence in BRCA1 mutation carriers. J Natl Cancer Inst 2002; 94: 1358-1365.

4. Thompson D, Easton D, Breast Cancer Linkage Consortium. Variation in cancer risks, by mutation position, in BRCA2 mutation carriers. Am J Hum Genet 2001; 68: 410-419.

5. Edwards SM, Kote-Jarai Z, Meitz J, Hamoudi R, Hope Q, Osin P, Jackson R, Southgate $C$, Singh R, Falconer A, Dearnaley DP, Ardern-Jones A, Murkin A, Dowe A, Kelly J, Williams S, Oram R, Stevens M, Teare DM, Ponder BA, Gayther SA, Easton DF, Eeles RA Cancer Research UK/Bristish Prostate Group UK Familial Prostate
Cancer Study Collaborators; British Association of Urological Surgeons Section of Oncology. Two percent of men with early-onset prostate cancer harbour germline mutations in the BRCA2 gene. Am J Hum Genet 2003; 72: 1-12.

† Abele A (Latvia); Altree M (Australia); Anagnostopoulos T (Greece); Ardern-Jones A (UK); Arver B (Sweden); Bancroft E (UK); Bangma C (The Netherlands); Bartsch G (Austria); Benitez J (Spain); Bevilacqua G (Italy); Blanco I (Spain); Bratt O (Sweden); Brewer C (UK); Brohet R (The Netherlands); Caldes T (Spain); Caligo M (ltaly); Chang-Claude J (Germany); Chapman C (UK); Chenevix-Trench G (Australia); Clowes V (UK); Cole T (UK); Cook J (UK); Cook M (UK); Cooper C (UK); Copakova L (Slovakia); Cruger D (Denmark); Cummings C (UK); Davidson R (UK); Dearneley D (UK); Donaldson A (UK); Dorkins H (UK); Douglas F (UK); Easton D (UK); Eccles D (UK); Eeles R (UK); Evans G (UK); Everaus H (Estonia); Eyfjord J (Iceland); Falconer A (UK); Fisher C (UK); Foster C (UK); Friedman E (Israel); Furhauser C (Austria); Gardovskis J (Latvia); Gerdes A-M (Denmark); Goldgar D (USA); Gregory H (UK); Grönberg H (Sweden); Haites N (UK); Hamdy F (UK); Heimdahl K (Norway); Hodgson S (UK); Ilencikova D (Slovakia); Irmejs A (Latvia); Izatt L (UK); Jóhannsson O (Iceland); Khoo V (UK); Kiemeny B (The Netherlands); Korn V (Austria); Kote-Jarai Z (UK); Kyriacou K (Cyprus); Lilja H (USA); Lilleby W (Norway); Lindeman G (Australia); Loman N (Sweden); Lubinski J (Poland); Luedtke-Heckenkamp K (Germany); Luleci G (Turkey); Lyubchenko L (Russia); Mæehle L (Nonway); Male A (UK); Manguoglu E (Turkey); Melia J (UK); Mitchell G (Australia); Mitra A (UK); Moller P (Norway); Moynihan C (UK); Nansalmaa M (Mongolia); Nicolai N (ltaly); Olah E (Hungary); Olsson H (Sweden); Osorio A (Spain); Osther P (Denmark); Ozbek U (Turkey); Papp J (Hungary); Paterson J (UK); AM, Peock S (UK); Peris M (Spain); Pichert G (UK); Radice P (Italy); Rajkumar T (India); Rennert G (Israel); Rookus M (The Netherlands); Salmon A (Israel); Schmutzler R (Germany); Schröder F (The Netherlands); Segura P (Spain); Sibley P (UK); Side L (UK); Stapleton A (Australia); Stratton M (UK); Suri M (UK); Suthers G (Australia); Taylor L (Australia); Thompson A (UK); Valdagni R (ltaly); van Asperen C (The Netherlands); van Leeuwen $F$ (The Netherlands); Vasen H (The Netherlands); Wagner T (Australia); Wilson P (UK); Yannoukakos D (Greece); Young M-A (Australia).

* This article reflects only the authors' views. The European Community is not liable for any use that may be made of the information contained therein. The information in this document is provided as is and no guarantee or warranty is given that the information is fit for any particular purpose. The user thereof uses the information at its sole risk and liability. 